\section{Dr. van Roon, et al reply}

\section{To the Editor:}

We thank Dr. Lambova for her interesting comment ${ }^{1}$ on our recent article published in The Journal ${ }^{2}$. We reported that a systemic sclerosis (SSc) or scleroderma-like capillaroscopic pattern is common in patients with Raynaud phenomenon, and can be frequently observed in patients with connective tissue diseases (CTD) other than SSc.

Dr. Lambova underlines the interesting point that a scleroderma-like capillaroscopic pattern could also be associated with presence of cutaneous digital vasculitis, which can be observed in a subset of patients with systemic lupus erythematodes (SLE) ${ }^{1}$. In a previous study from Dr. Lambova's group, this pattern was observed in 2/4 patients with digital vasculitis ${ }^{3}$. Although this is a very interesting point, our retrospective database was not set up to answer this specific question. Only 30 patients from our study were classified as having SLE, of which 7 had cutaneous abnormalities of the fingers. In only $2 / 30$ patients, the clinical diagnosis of digital vasculitis was made, of whom 1 had a scleroderma-like pattern and the other did not.

We agree with Dr. Lambova that a scleroderma-like capillaroscopic pattern is not specific for SSc, and as our study points out is frequently observed in other CTD. This has already been reported in the early studies on nailfold capillary microscopy ${ }^{4}$. A scleroderma-like capillaroscopic pattern is characterized by typical changes to the nailfold capillaries such as giant loops, neovascularizations, and capillary loss. Although morphologic changes are frequently observed in SLE, and some authors report associations with clinical disease variables and possibly activity, a scleroderma-like capillaroscopic pattern is relatively rare in $\mathrm{SLE}^{5}$. These abnormalities have been shown to be associated with vasculopathic changes in capillaroscopically guided nailfold biopsy studies, characterized by basal lamina thickening, perivascular cellular infiltrates, fibrosis, and edema in histology and electron microscopy ${ }^{6}$. Our study does support associations with vasculopathy in other organs, as confirmed by a recent study showing that a scleroderma pattern in SLE was associated with pulmonary arterial hypertension ${ }^{7}$. However, to the best of our knowledge, although several studies of nailfold capillaroscopy have been performed in SLE, none has addressed the association with digital vasculitis structurally.

A major challenge in studying digital vasculitis is that its diagnosis is based on clinical grounds; it is generally not demonstrated by objective imaging or histopathologic studies. Cutaneous lesions of the digits in SLE are polymorphous, and not always classified correctly. This is emphasized by a study that found histopathological confirmation of vasculitis in only a small proportion of SLE patients with digital lesions that were clinically diagnosed as vasculitis ${ }^{8}$.

We stress the comment of Dr. Lambova that a scleroderma- like pattern is associated with other CTD than SSc alone. However, although the hypothesis of a link of the pattern with digital vasculitis is a very interesting one, we cannot confirm it with our data, and strongly suggest that it be addressed in a well-designed prospective study.
ANNIEK M. VAN ROON (D, MD, PhD, Department of Internal Medicine, Division of Vascular Medicine, University of Groningen, University Medical Center Groningen; KARINA DE LEEUW, MD, PhD, Department of Rheumatology and Clinical Immunology, University of Groningen, University Medical Center Groningen; DOUWE J. MULDER, MD, $\mathrm{PhD}$, Department of Internal Medicine, Division of Vascular Medicine, University of Groningen, University Medical Center Groningen, Groningen, the Netherlands. Address correspondence to Dr. D.J. Mulder, Department of Internal Medicine, Division of Vascular Medicine, University Medical Center Groningen, Huispostcode AA41, Hanzeplein 1, Postbus 30 001, Groningen, the Netherlands.E-mail: d.j.mulder@umcg.nl

\section{REFERENCES}

1. Lambova SN. Scleroderma-like pattern in various rheumatic diseases. J Rheumatol 2020;47:942.

2. Van Roon AM, Huisman CC, van Roon AM, Zhang D, Stel AJ, Smit AJ, et al. Abnormal nailfold capillaroscopy is common in patients with connective tissue disease and associated with abnormal pulmonary function tests. J Rheumatol 2019;46:1109-16.

3. Lambova SN, Muller-Ladner U. Capillaroscopic pattern in systemic lupus erythematosus and undifferentiated connective tissue disease: what we still have to learn? Rheumatol Int 2013;33:689-95.

4. Maricq HR, LeRoy EC, D’Angelo WA, Medsger TA, Rodnan GP, Sharp GC, et al. Diagnostic potential of in vivo capillary microscopy in scleroderma and related disorders. Arthritis Rheum 1980;23:183-9.

5. Cutolo M, Melsens K, Wijnant S, Ingegnoli F, Thevissen K, De Keyser F, et al. Nailfold capillaroscopy in systemic lupus erythematosus: a systematic review and critical appraisal. Autoimmun Rev 2018;17:344-52.

6. von Bierbrauer A, Barth P, Willert J, Baerwald C, Mennel $\mathrm{HD}$, Schmidt JA. Electron microscopy and capillaroscopically guided nailfold biopsy in connective tissue diseases: detection of ultrastructural changes of the microcirculatory vessels. Br J Rheumatol 1998;37:1272-8.

7. Donnarumma JFS, Ferreira EVM, Ota-Arakaki J, Kayser C. Nailfold capillaroscopy as a risk factor for pulmonary arterial hypertension in systemic lupus erythematosus patients. Adv Rheumatol 2019;59:1-5.

8. Bouaziz JD, Barete S, Le Pelletier F, Amoura Z, Piette JC, Frances C. Cutaneous lesions of the digits in systemic lupus erythematosus: 50 cases. Lupus 2007;16:163-7.

First Release April 15 2020; J Rheumatol 2020;47:6; doi:10.3899/jrheum.200136 